This is an Author's Accepted Manuscript of an article published in Memory, 21:2, 280-284, DOI: 10.1080/09658211.2012.729598 (copyright Taylor \& Francis), available online at: http://www.tandfonline.com/10.1080/09658211.2012.729598

This is an Author's Accepted Manuscript of an article published in Memory, 21:2, 280-284, DOI: 10.1080/09658211.2012.729598 (copyright Taylor \& Francis), available online at: http://www.tandfonline.com/10.1080/09658211.2012.729598

Changes resulting from the publishing process, such as peer review, editing, corrections, structural formatting, and other quality control mechanisms may not be reflected in this document. Changes may have been made to this work since it was submitted for publication.

Warm-up Questions on Early Childhood Memories Affect the Reported Age of Earliest Memories in Late Adolescence

\author{
Osman S. Kingo* \\ Annette Bohn** \\ Peter Krøjgaard**
}

* Center on Autobiographical Memory Research, Department of Psychology and Behavioral Sciences, and MINDLab, Aarhus University.

** Center on Autobiographical Memory Research, Department of Psychology and

Behavioral Sciences, Aarhus University.

Corresponding Author:

Osman S. Kingo,

Center on Autobiographical Memory Research,

Department of Psychology and Behavioral Sciences,

Aarhus University,

Bartholins Allé 16

DK-8000 Aarhus C.

Denmark

Phone: +45 87165862 (direct)

Fax: +45 89424901

Email: osman@psy.au.dk 
This is an Author's Accepted Manuscript of an article published in Memory, 21:2, 280-284, DOI: 10.1080/09658211.2012.729598 (copyright Taylor \& Francis), available online at: http://www.tandfonline.com/10.1080/09658211.2012.729598

\begin{abstract}
Researchers have recently used warm-up questions concerning childhood memories at specific early ages (e.g. three years of age) in an attempt to facilitate the retrieval process on the subsequent question regarding the earliest memory. Although this methodology may indeed facilitate the retrieval process by conducting the test in a manner resembling ordinary dialogue, the methodology might also unintentionally put further demand characteristics on the respondents. In the present study we systematically manipulated the target age (either three or six years of age) for the warm-up question preceding the 'earliest memory' question in order to test this possibility. The participants were 445 Danish high school students $\left(M_{\text {age }}\right.$ $=17.94)$. The results revealed that systematically manipulating the target age for the warmup question had a strong impact on the age of the earliest memory reported by the adolescents. Participants who received warm-up questions with three years as the target age subsequently reported earlier first memories than the participants receiving warm-up questions with six years as the target age. These results have important implications for the methodology involved in research on childhood amnesia.
\end{abstract}

Acknowledgement: The present study was supported by The Danish National Research Foundation and MINDLab. We thank Inger Birschall Nielsen for her help with the data collection. 
This is an Author's Accepted Manuscript of an article published in Memory, 21:2, 280-284, DOI: 10.1080/09658211.2012.729598 (copyright Taylor \& Francis), available online at: http://www.tandfonline.com/10.1080/09658211.2012.729598

\section{Warm-up Questions on Early Childhood Memories Affect the Reported Age of Earliest Memories in Late Adolescence}

The term childhood amnesia, originally coined by Freud (1905/1953), refers to the inability in adults to recall specific events from their first years of life. Studies on adults' earliest memories have typically shown that adults' first memories can be dated back to the time when the respondents were between 3-4 years of age (e.g., Howes, Siegel, \& Brown, 1993; Jack \& Hayne, 2007; Kihlstrom \& Harachiewicz, 1982; Mullen, 1994; Wang, Conway, \& Hou, 2004).

Recently, researchers have begun to ask children in various age groups about their earliest memories (e.g. Bauer, Burch, Scholin, \& Güler, 2007; Jack, MacDonald, Reese, \& Hayne, 2009; C. Peterson, Warren, \& Short, 2011; Reese, Jack, \& White, 2010; Tustin \& Hayne, 2010). Two of these studies have shown that children seem to have clearly earlier first memories than adults (Jack et al., 2009; Tustin \& Hayne, 2010). Meanwhile, these two studies obtaining earlier memories in children have both used the recently developed ‘timeline' methodology where each year in the participants' life is marked on a large timeline template made of cardboard and supplemented by photographs from the participants' childhood (Tustin \& Hayne, 2010). Another distinctive feature of the timeline methodology is that the data collection procedure to a larger extent resembles ordinary dialogue instead of just asking questions about the first memory as is often done with adults. The typical procedure of asking about first memories out of context may be experienced as odd by participants (Pillemer \& White, 1989), but in the timeline method such a context is built initially: Before the target question is finally asked, the participants are asked about 
This is an Author's Accepted Manuscript of an article published in Memory, 21:2, 280-284, DOI: 10.1080/09658211.2012.729598 (copyright Taylor \& Francis), available online at: http://www.tandfonline.com/10.1080/09658211.2012.729598

memories for events at different specific ages - - for example at age 10, 5, 3, and before 3 years of age, and earliest memory (Jack et al., 2009), or recently, at 3, before 3 years of age, and earliest memory (Tustin \& Hayne, 2010). This methodology has led to impressively early first memories e.g., $M_{\text {age }}=2.33$ years of earliest memories in 12-13 year old children, (Jack et al., 2009) and $M_{\text {age }}=23$ months with young adults (Jack \& Hayne, 2010). The use of warm-up questions in relation to earliest memories is not limited to the timeline methodology. Other methodologies have in similar ways asked for early childhood memories before asking for the earliest memory, such as in the memory fluency task, resulting in similar ages for earliest memories: e.g. $M_{a g e}=28.2$ months (8-, 11-, and 14-yearolds,Western sample; C. Peterson, Wang, \& Hou, 2009).

Based on Pillemer and White’s (1989) reservations with regards to just asking the participants about their earliest memories -- especially when the participants are not adults -the rationale behind the use of warm-up questions seems perfectly justified. However, one might speculate how warm-up questions help the children to report very early memories. Asking warm-up questions about memories from age three, and subsequently before age three -- before posing the target question on earliest memory - may very well by itself be facilitative of retrieval but may also implicitly inform the respondent that such early memories are expected by the experimenter, which may have led to earlier memory reports than obtained otherwise. Such “expectancy” effects would be similar to those created by social modeling as reported by T. Peterson, Kaasa, and Loftus (2009). We do not doubt the results of the studies using warm-up questions, because in most cases the authors carefully checked the content and accuracy of the reported events by asking the parents of the participating children, and the accuracy was indeed high (e.g. Jack et al., 2009; C. Peterson 
This is an Author's Accepted Manuscript of an article published in Memory, 21:2, 280-284, DOI: 10.1080/09658211.2012.729598 (copyright Taylor \& Francis), available online at: http://www.tandfonline.com/10.1080/09658211.2012.729598

et al., 2009; Tustin \& Hayne, 2010). However, the hypothesis that warm-up questions concerning childhood memories from a specific early age period (e.g. three years of age) might affect the responses on the subsequent question on the same subject's earliest memory has never been directly tested. Such a test would be an important step in establishing how warm-up questions affect responses regarding earliest memories. In this study, we warmed participants up by asking about a recent memory, and then either about a memory from around the age of three, (the Early condition) or about a memory from around the age of six (the Late condition). Due to the difference in the questions for these two conditions we expected the participants in the Early condition to have earlier earliest memories than their peers in the Late condition.

\section{The Study}

\section{Participants:}

A total of 682 Danish high school students participated in the experiment. Participants who did not provide a complete questionnaire were excluded from the analysis, leaving 445 participants (323 girls, $M_{\text {age }}=17.84$ years, $S D=1.15 ; 122$ boys, $M_{\text {age }}=18.20$ years, $S D=$ 1.67) range: $15.33-25.04$ years. The participants were not compensated for their participation.

\section{Materials and Procedure:}

Half of the students received the Early version, and the other half received the Late version. However, since the distribution of the rather large proportion of participants that failed to fill out the questionnaire correctly was skewed, we ended up having 184 participants in the Early version (139 girls, $M_{\text {age }}=17.78$ years, $S D=1.17 ; 45$ boys, $M_{\text {age }}=$ 18.52 years, $S D=2.08$; range: $15.33-15.83$ years) and 261 participants in the Late version 
This is an Author's Accepted Manuscript of an article published in Memory, 21:2, 280-284, DOI: 10.1080/09658211.2012.729598 (copyright Taylor \& Francis), available online at: http://www.tandfonline.com/10.1080/09658211.2012.729598

(184 girls, $M_{\text {age }}=17.88$ years, $S D=1.14 ; 77$ boys, $M_{\text {age }}=18.01$ years, $S D=1.36$; range: 15.33-23.33 years). The two versions were identical except for the manipulation previously described (and see below). The participants were given the following written instruction:

On the following pages, we will ask you about memories from your life. All the questions concern specific events you have experienced (e.g. your confirmation or a specific visit at restaurant $\mathrm{X}$ ) and not about recurring events (e.g. family celebrations in general or what you typically experience when you go to a restaurant).

- Please only tell about events that you actually remember to have experienced.

- $\quad$ Please answer the questions as precise as possible.

- Please respond to the questions in the specific order in which they are given.

Participants provided their gender and age. First, participants were asked to recall a recent event (that had taken place within the last two years), then a childhood event from around the age of three [Early condition], or six [Late condition] and finally, they were asked to recall their earliest memory. In each section they were instructed to briefly describe the event in two lines, and subsequently to state how old they were, when the event took place.

\section{Results:}

The overall means and standard deviations are presented in Table 1. The means displayed regarding the age at Recent memories and Targeted memories (the reported age when asked specifically for a memory from around the age of either three or six years) respectively suggest that the respondents did indeed report recent memories (i.e. close to 
This is an Author's Accepted Manuscript of an article published in Memory, 21:2, 280-284, DOI: 10.1080/09658211.2012.729598 (copyright Taylor \& Francis), available online at: http://www.tandfonline.com/10.1080/09658211.2012.729598

their current age), memories from around three years, or from around six years as intended by the questions.

\section{Table 1}

In order to investigate the impact of the experimental manipulation, we conducted a 2 x 2 ANOVA with gender (male vs. female), and condition (Early vs. Late), as between subjects factors and age at earliest memory as dependent variable. This analysis revealed a very strong main effect of condition, $F(1,441)=31.38, p<.001, \eta_{p}{ }^{2}=.07$. As hypothesized, the respondents in the Early condition reported significantly earlier first memories $\left(M_{\text {Early }}=\right.$ 2.41 years, $S D=.83)$ than the respondents in the Late condition $\left(M_{\text {Late }}=3.16, S D=1.31\right)$. No significant gender difference or interactions were obtained (all p’s > .28).

As already stated, the participants who had failed to hand in complete questionnaires were excluded from the sample. However, when considering those respondents who only failed to provide an answer for the warm-up childhood event from around either age three (Early) or age six (Late), caution may be needed. The argument for excluding these respondents is that unless they had provided an answer for the warm-up childhood episode, the experimental manipulation would have had no chance to come into effect, and consequently the overall design would be flawed. However, the potential drawback of excluding these respondents was the risk of producing a sample bias effect. To illustrate, some of the respondents that had failed to provide an answer specifically for the warm-up childhood event around three years of age may have done so simply because their earliest memories were older than from around three years of age. The fact that there were 
This is an Author's Accepted Manuscript of an article published in Memory, 21:2, 280-284, DOI: 10.1080/09658211.2012.729598 (copyright Taylor \& Francis), available online at: http://www.tandfonline.com/10.1080/09658211.2012.729598

considerably more drop-outs in the Early group relative to the Late group suggests that this might indeed have been the case. Thus, in order to investigate this potential sample bias, we decided to repeat the ANOVA presented above on a sample $(n=494)$ including those respondents $(\mathrm{n}=49)$ who had not provided an answer for the specific warm-up childhood event around three $(n=38)$ or six $(n=11)$ years of age. In preliminary analysis we found no age $(t(492)=1.19, p>.2)$ or gender $\left(\chi^{2}(1)=.23, p>.6\right)$ differences between the group who completed the questionnaire and those who did not. For this inclusive sample, the ANOVA again showed a significant main effect of condition, $F(1,490)=11.39, p<.001, \eta_{p}{ }^{2}=.023$. Again, the respondents who were asked to report pre-test childhood memories from around the age of three $\left(M_{\text {Early-inclusive }}=2.72\right.$ years, $\left.S D=1.30\right)$ reported significantly earlier first memories than the participants who were asked to report pre-test childhood memories from around the age of six $\left(M_{\text {Late-inclusive }}=3.23\right.$ years, $\left.S D=1.36\right)$. No other main effect or interaction was obtained (all p’s > .4).

Finally, we ran the ANOVA again this time only for the 49 respondents who had not provided an answer for the age-specific warm-up question. This analysis showed no significant main effect of condition, $F(1,45)=.96, \eta_{p}{ }^{2}=.023$, even though there was a tendency for participants in the Early condition to report earlier first memories $\left(M_{\text {Early-noncompl }}\right.$ $=4.24$ years, $S D=1.97)$ than participants from the Late condition $\left(M_{\text {Late-noncompl }}=4.76\right.$ years, $S D=1.91$ ). The total mean age of earliest memory for these 49 respondents was 4.35 years, $S D=1.95$; which was significantly higher than for the group of 445 "completers” $t(492)=7.75, p<.001$. No other main effect or interaction was obtained (all $p$ 's $>.4$ ). 
This is an Author's Accepted Manuscript of an article published in Memory, 21:2, 280-284, DOI: 10.1080/09658211.2012.729598 (copyright Taylor \& Francis), available online at: http://www.tandfonline.com/10.1080/09658211.2012.729598

\section{Discussion}

This is the first study to show that manipulating the specific age point (i.e. three vs. six years of age) to which a given warm-up question on an early childhood memory is related could influence subsequent reports on the age of earliest memories. The respondents who were asked a warm-up question regarding a specific episode around the age of three provided significantly earlier memories than those who had received warm-up questions regarding episodes from around the age of six.

The present setup cannot tell us exactly why our manipulation made a difference. As suggested earlier it could be that merely asking about memories from around the age of three may implicitly inform the respondent that such early memories are expected by the experimenter, leading to earlier reports of first memories than otherwise -- in line with the effect social expectation on the report of early autobiographical memories found by $\mathrm{T}$. Peterson et al. (2009). On the other hand, it could be that recalling one memory from this early age triggers or facilitates other early memories thereby making it easier to recall very early first memories. If we look at the analysis of the small group of 49 respondents who did not provide an answer to the "age biased” warm-up question (the non-completers) we see that the Early condition group does report earlier first memories than the Late condition group. Even if the difference is not significant in this analysis, the effect size $\left(\eta_{p}{ }^{2}=.023\right)$ equals that found in the ANOVA of the full 494 participants. This suggests that merely reading the age-biased question (but not recalling and providing a memory) has some effect on the report of the earliest memory by itself, which in turn lends some support to the social expectation explanation; while the fact that the mean age for the 49 non-completers' earliest memory was significantly higher than for the rest supports the explanation that the warm-up 
This is an Author's Accepted Manuscript of an article published in Memory, 21:2, 280-284, DOI: 10.1080/09658211.2012.729598 (copyright Taylor \& Francis), available online at: http://www.tandfonline.com/10.1080/09658211.2012.729598

questions facilitate retrieval of these early memories after other early memories have been retrieved. In all likelihood both factors are in play, but clearly, additional manipulations are required if we are to fully establish why the different warm-up questions make a difference.

We obtained mean ages at earliest memory $\left(M_{\text {total }}=2.85\right.$ years $)$ that were somewhat lower than is typically found in the literature (e.g., 3-4 years of age). One obvious explanation is that all our respondents were given warm-up questions concerning early childhood memories. As outlined in the introduction, other studies (e.g. Jack et al., 2009; C. Peterson et al., 2009); Tustin \& Hayne, 2010) that have incorporated warm-up questions also obtained earlier first memories than expected in the existing literature. Thus, our findings are in line with results from similar studies.

Whereas some studies report gender differences on earliest memories (Howes et al., 1994; Mullen, 1994, Study II; C. Peterson et al., 2009) we found no gender differences in the present sample. However, other studies have also failed to obtain gender differences among college students (e.g., Wang, 2001) as well as in late adolescents (C. Peterson et al., 2005).

Do the results of the present study suggest that warm-up questions should be avoided when investigating earliest memories? We do not think so. Following the arguments from Pillemer and White's (1989) seminal review, the standard way of posing direct questions regarding the very first memory may not be the most valid method when collecting data on earliest memories. And as evidenced from the studies using the timeline approach, as well as the results from the study presented here, warm-up questions may facilitate earlier recollections. This has important implications for our current estimates of the age of people's earliest memories since these may be incorrect given the nature of the questions that participants are typically asked. However, the results from the present study also provide 
This is an Author's Accepted Manuscript of an article published in Memory, 21:2, 280-284, DOI: 10.1080/09658211.2012.729598 (copyright Taylor \& Francis), available online at: http://www.tandfonline.com/10.1080/09658211.2012.729598

evidence that the specific nature and target ages of warm-up questions do influence the report of age at earliest memories. This is important information for researchers planning to use such warm-up questions as part of their investigations of the earliest memories of children and adults. The present study thus adds a small, but important building block to the methodological toolbox, when attempting to investigate the very first memories of our lives. 
This is an Author's Accepted Manuscript of an article published in Memory, 21:2, 280-284, DOI: 10.1080/09658211.2012.729598 (copyright Taylor \& Francis), available online at: http://www.tandfonline.com/10.1080/09658211.2012.729598

\section{References:}

Bauer, P.J., Burch, M.M., Scholin, S.E., Güler, O.E. (2007). Using cue words to investigate the distribution of autobiographical memories in childhood. Psychological Science, 18, 910-916.

Freud, S. (1905/1953). Three essays on the theory of sexuality. In: J. Strachey (Ed.), The Standard Edition of the Complete Psychological Works of Sigmund Freud, vol. 7. (pp. 125-248). London: Hogarth Press.

Howes, M., Siegel, M, \& Brown, N. (1993). Early childhood memories: Accuracy and effect. Cognition, 47, 95-119.

Jack, F., \& Hayne, H. (2007). Eliciting adults’ earliest memories: Does it matter how we ask the question? Memory, 15, 647-663.

Jack, F., \& Hayne, H. (2010). Childhood amnesia: Empirical evidence for a two-stage phenomenon. Memory, 18, 831-844.

Jack, F., MacDonald, S., Reese, E., \& Hayne, H. (2009). Maternal reminiscing style during early childhood predicts age of adolescents' earliest memories. Child Development, 80, 469-505.

Kihlstrom, J. F., \& Harackiewicz, J. M. (1982). The earliest recollection: A new survey. Journal of Personality, 50, 134-148.

Mullen, M. K. (1994). Earliest recollections of childhood: A demographic analysis. Cognition, 52, 55-79.

Peterson, C., Grant, V., \& Boland, L. (2005). Childhood amnesia in children and adolescents: Their earliest memories. Memory, 13, 622-637. 
This is an Author's Accepted Manuscript of an article published in Memory, 21:2, 280-284, DOI: 10.1080/09658211.2012.729598 (copyright Taylor \& Francis), available online at: http://www.tandfonline.com/10.1080/09658211.2012.729598

Peterson, C., Warren, K. L., \& Short, M. M. (2011). Infantile Amnesia Across the Years: A 2-Year Follow-up of Children’s Earliest Memories. Child Development, 82, 10921105.

Peterson, C., Wang, Q., \& Hou, Y. (2009) "When I was little”: Childhood recollections in Chinese and European Canadian grade school children. Child Development, 80 (2), 506-518.

Peterson, T., Kaasa, S.O., \& Loftus, E.F. (2009). Me too!: Social modelling influences on early autobiographical memories. Applied Cognitive Psychology, 23 (2), 267-277. doi: 10.1002/acp.1455.

Pillemer, D.B., \& White, S.H. (1989). Childhood events recalled by children and adults. In H.W. Reese (Ed.), Advances in child development and behavior, Vol. 21 (pp. 297340). Orlando, FL: Academic Press.

Reese, E., Jack, F., \& White, N. (2010). Origins of adolescents’ autobiographical memories. Cognitive Development, 25, 352-367

Tustin, K., \& Hayne, H. (2010). Defining the boundary: Age-related changes in childhood amnesia. Developmental Psychology, 46, 1049-1061.

Wang, Q. (2001). Culture effects of adults' earliest childhood recollection and selfdescription: Implications of the relation between memory and self. Journal of Personality \& Social Psychology, 81, 220-233.

Wang, Q., Conway, M., \& Hou, Y. (2004). Infantile amnesia: A cross-cultural investigation. Cognitive Sciences, 1, 123-135. 
This is an Author's Accepted Manuscript of an article published in Memory, 21:2, 280-284, DOI: 10.1080/09658211.2012.729598 (copyright Taylor \& Francis), available online at: http://www.tandfonline.com/10.1080/09658211.2012.729598

Table 1

Mean age in years (SD's in parenthesis) at Recent, Targeted, and Earliest memories across gender and Conditions

\begin{tabular}{ccccc}
\hline & & Age at Recent & Age at Targeted & Age at Earliest \\
The Early condition & All & $17.12(1.62)$ & $3.29(0.57)$ & $2.41(0.83)$ \\
& Males & $17.71(2.25)$ & $3.29(0.62)$ & $2.46(0.86)$ \\
& Females & $16.92(1.31)$ & $3.30(0.56)$ & $2.39(0.82)$ \\
\hline The Late condition & All & $17.08(1.31)$ & $6.12(0.53)$ & $3.16(1.31)$ \\
& Males & $17.23(1.41)$ & $6.12(0.53)$ & $3.02(1.48)$ \\
& Females & $17.02(1.26)$ & $6.10(0.53)$ & $3.22(1.23)$ \\
\hline
\end{tabular}

a. The reported age when asked specifically for a memory from around the age of either three or six years. 